\title{
The Future of Enterprise Systems in Africa: Bleak or Bright?
}

\author{
${ }^{1}$ Ebem, D.U1., ${ }^{2}$ Ebem C.C \& ${ }^{1}$ Onyianta, J.O. \\ 1Department of Computer Science University of Nigeria, Nsukka. \\ ${ }^{2}$ Research Assistant, Amaka Consultancy Services, Nig., 10 lkpeze Close Trans Ekulu, Enugu. \\ deborah.ebem@unn.edu.ng, ,johnnyspencer210@gmail.com \\ Nigeria.saintcaleb3@gmail.com \\ Phones: +234 $8052810722 ;+2348062923028$
}

\begin{abstract}
Africa is gradually getting involved in the implementation of enterprise resource systems, notwithstanding the challenges. Lack of standardized processes, infrastructure, support and maintenance systems have been identified as key issues/challenges with Africa in the implementation of IT based systems, which include enterprise system. The untapped potentials and a wide range of untouched market for Enterprise Resource Planning (ERP) systems lie within Africa. Great care must be taken by ERP vendors and developers, implementing enterprises and other stakeholders to harness these resources by first of all, making sure that the implementation environment, skilled IT staff, support and maintenance systems are well set. This paper explored the future of enterprise resource planning systems in Africa and has suggested areas that need the attention of both vendors and implementation enterprises. The study was exploratory in nature and made use of secondary information from textbooks and journals. A desk research approach was employed where literature material on Enterprise Systems implementation process and challenges were examined. Based on the outcome of the review, an evolutional framework was proposed for ERP implementation for Africa. Proper implementation of the framework would yield the needed result. Future research was recommended to empirically test and refine the framework and explore the relationships among the various variables.
\end{abstract}

Keywords: Systems, technology, enterprise resource planning (ERP), IT, infrastructure, e-commerce.

CISDI Journal Reference Format

Ebem, D.U., Ebem C.C \& Onyianta, J.O. (2019): The Future of Enterprise Systems in Africa: Bleak or Bright?. Computing, Information Systems, Development Informatics \& Allied Research Journal. Vol 10 No 1.Pp 1-16. Available online at www.cisdijournal.org DOI Affix - https://doi.org/ 10.22624/AIMS/CISDI/V10N2P1

\section{INTRODUCTION}

Enterprise systems is a generic name for an enhanced Enterprise Resource Planning (ERP) system which supports ecommerce and m-commerce using wireless technologies (mobile technologies and the internet) (McGaughey and Gunasekaran 2007). ERP is an information system that processes and facilitates real-time transactions using an integrated approach (O'Leary 2000). ERP systems integrate processes, people, data and applications in such a way that different aspects of an organization share enterprise resources, thereby reducing the system cost associated with running the business to a minimum (Beheshti and Beheshti, 2010). Enterprises incur costs in the bid to make products and services available to consumers. Systems integration is achieved in ERP system as vendors, and software developers view different aspects of the organization as separate but related entities and as such design and develop modules to handle them. With ERP systems, organizational and corporate goals are realized, and performance is improved (Markus et al. 2000, Moalagh 2012). 
Globalization brought about by technological advancement has led to the emergence of a borderless economic environment where firm's competitors and marketplaces are no longer limited by geographical boundaries but are widely spread across the globe. Firm's competitors are no longer those from the domestic environment alone, but also include similar firms in other parts of the globe. With the above scenario, most developing countries are buying into the use of Information and Communication Technologies (ICT) in handling business processes with ERP systems not being left out (Kumar) (2016).

Even though developing nations are at different levels of ERP implementation, a wide gap still exists between developed and developing countries on ERP systems and application (Huang 2001, Kam 2012, Serima, (2014).For instance, Suraj (2016) noted that India had achieved a significant level of growth in its economy and an admirable growth in its ERP systems implementation. Most countries in Africa are yet to attain this level of growth and development on ERP systems adoption and implementation (Tobie et al 2016). Part of the reason behind this drawback includes lack of adequate infrastructure, apathy to the use of ICT infrastructure, lack of standardized business processes and lack of skilled IT personnel.

Despite the above challenges, the potentials of ERP adoption and implementation for developing countries are huge and have remained grossly untapped. Many studies have been carried out on enterprise resource planning, but only a few exist on future of ERP as it relates to the type of economy (developed, developing and least developed). Therefore, this paper intends to fill this gap in the literature by assessing the future of ERP systems for Africa. This paper is divided into the following sections: introduction, objective of the study, research approach, literature review, challenges and issues of enterprise systems implementation in developing countries, ERP of the future from a global perspective and the position of Africa, developing a framework for the future of enterprise systems in Africa, the way forward and a conclusion.

\subsection{Objectives of the Study}

The objectives of the study are:

1) To identify current challenges and issues that hinder the implementation of ERP systems in organizations from developing countries.

2) To review the future of ERP implementations from a global perspective.

3) To propose an evolutional framework for future implementation of ERP systems in Africa.

\subsection{Research Approach}

The study was exploratory in nature and made use of secondary information from relevant textbooks and journals. A desk research approach was employed where literature material on Enterprise Systems implementation process and challenges were examined. Based on the outcome of the review, an evolutional framework was proposed for ERP for Africa.

\section{LITERATURE REVIEW ON ERP SYSTEM IMPLEMENTATION IN DEVELOPING COUNTRIES.}

Enterprise Resource Planning (ERP) is an information system that integrates business processes with the aim of creating value and reducing costs by making the right information available to the right people at the right time to help them make sound decisions in managing resources productively and proactively (McGaughey \& Gunasekaran, 2007). It is a software solution that integrates business functions and data into a single system to be shared within a company. It is also a real-time information sharing system that eliminates process redundancies and increases efficiency to support services. Enterprise System (ES)/ERP implementation has been described by Herold et al. 2007 as one of the most common organizational change events. 
Lots of literature abound in ERP implementations and adoptions in developed countries (Esteves and Pastor (2001), Botta-Genoulaz et al. (2005), Moon (2006), Momoh and Sheba (2010), Grabski et al. (2011). Kataev et al (2013) discussed the current status and the major trend of Enterprise System in Russia 1992 -2012. They identified the following as the issues that prevented Western ERP systems from being rapidly adopted in Russia: 1) Lack of rapid progress. 2) Russian enterprises need to re-engineer business process constantly unlike Western enterprises that support all accepted world standards.3) There are differences between Russian and Western accounting systems. 4) A number of the modules in Western ERP systems such as human resource management and accounting compose changing Russian legislation constantly. They stated that the major trend of Russian ES development is moving towards emphasising fully integrated ES. Secondly, that Russian business is looking for continuous improvement of the performance of ES. They are open to the new, cost-effective, process-oriented and security efficient technologies, such as cloud computing. O.Zach et al (2012) investigated how SME context affects ERP system implementation. The companies' type of ownership and limited resources were identified as the most influential contextual factors. The implementation phase was the most affected by the SME context. Sanja (2013) presented the Zambia smartcare system that reduced the use of paperwork on health clinic staff. He also listed other countries in Africa that have implemented ERP.

Tobie et al (2016) reviewed ERP implementation in African countries. They reviewed 26 articles and defined a frame for searching for topics and presented a bibliography of the studies and the actual context of ERP implementation in Africa. Their paper highlighted open issues that can be tackled in future research in the development of African countries driven by ERP. The paper also discussed whether the implementation of ERP is an important topic or a market place in the African content. Finally, it drew some recommendations that will contribute to the successful implementation of ERP within African countries. They suggested that their review should be extended with other possible missing papers since it was not exhaustive.

Keel and Wynn (2015) analyzed the implementation of a SAP ERP R/3 within a Libyan Oil Company. They defined a good implementation strategy that was critical to the success. Boltena and Gomez (2012) focused on understanding the reasons that underpinned the implementation success in an African country. They followed a case study approach to experiment with the implementation of a Microsoft ERP in an Ethiopian medium sized organization.

Akeelet et al. (2013) defined a framework for ERP implementation in a developing context. The framework consists of six steps given as follows: identify top level business processes, develop systems portfolio map, allocate information system (IS) to process/sub-process areas and undertake red amber green (RAG) analysis, assess IS function against Nolan's model, apply Zuboff's model at process level, and apply McFarlan-Peppard. The framework was validated on two case studies that used two different strategies of ERP implementation. The first strategy consisted of implementing a SAP ERP and the second strategy was an in-house development in two Libyan Oil companies. With this framework, it was possible to trace the deployment on each context and thus the implementation process at each step (Tobie, et al, 2016).

Mukwasi and Seymour (2015) examined casual and resultant risks associated with ERP systems adoption by African Small and Medium-sized Enterprises (SMEs). By following a qualitative study in South- Africa and Zimbabwe, they defined a risk interdependence framework that reports the risks and their causes. The authors raised the need for more studies to understand how risks are executed and hence define good policies to manage them. To help South African SMEs define a business case, Mukwasi and Seymour (2012) developed a framework that identifies the direct and indirect costs, the benefits and the risks associated with the implementation of ERP. To make easy the cost estimation process, Mukwasi and Seymour (2014) proposed a cost estimation model. The model included some categories like hardware cost, software cost, implementation cost and broader organization cost. 
Several studies investigated factors that influence ERP adoption in African countries. In South Africa, Seymour and van Vuuren (2014) believe that job and perceived value of the system impact negatively on user adoption in SME's context. In Kenya, organizational composite factors effectively influence the adoption, whereas planned change, business environment and ERP attribute factors are reported to be weak predictors of a successful ERP adoption (Nzuki \& OkeloOdongo, 2015). Malie et al (2008) identified the factors that motivate the acquisition of an ERP system by South African SME. The factors are reliability, service and support, compatibility, vision of the vendor, industry knowledge, flexibility, vendor references, organizational fit, functionality, infrastructure, implementation time, market position of vendor, affordability, corporate compliance. An understanding of how these factors impact on the acquisition process may help in the selection of the appropriate ERP (Tobie et al 2016).

ERP systems can be delivered as Software as a Service (SaaS).This is an example of off premise and can reduce both hardware and software cost. This type of ERP is increasingly adopted in the global market (Tobie et al 2016), but in Africa this approach is seldom encountered (Lechesa et al,2012).Presently some universities in Africa are now members of SAP University Alliances. These universities are training staff and students on SAP ERP and enterprise system as a course. African universities that join the Enterprise System Education For Africa (ESEFA) programme can integrate the Enterprise Systems (ES) curriculum content into their business and technical study programmes. The modular curriculum design helps universities to adapt courses and learning material to meet their course requirements. Trainthe-Lecturer courses with an associated ES Fundamentals qualification by SAP University Alliances assists lecturers in gaining the requisite enterprise systems and curriculum alignment knowledge required to teach enterprise systems in the curricula ${ }^{1}$.Table 1 below gives the names of African Countries and universities that are members of SAP University Alliance/ESEFA partners and the region.

Table 1: ESEFA Partners

\begin{tabular}{|l|l|l|l|}
\hline S/N & Country & Name of Universities & Region \\
\hline 1 & South Africa & $\begin{array}{r}\text { 1. University of Cape Town } \\
\text { 2. University of Pretoria } \\
\text { 3. Nelson Mandela Metropolitan University }\end{array}$ & South \\
\hline 2 & Kenya & $\begin{array}{r}\text { Strathmore University } \\
\text { 1. University of Ibadan }\end{array}$ & East \\
\hline 3 & Nigeria & University of Nigeria, Nsukka. & West \\
\hline 4 & Tanzania & University of Dar-es-Salaam & East \\
\hline 5 & Zambia & University of Zambia & South \\
\hline 6 & Ghana & African University College of Accountancy & West \\
\hline 7 & Mauritius & University of Mauritius & South East \\
\hline 8 & Namibia & Namibia University of Science and Technology & South \\
\hline 9 & Botswana & 1. University of Botswana & South \\
\hline 10 & Ethiopia & Addis Ababa University & East \\
\hline
\end{tabular}

Source : ${ }^{1}$ http:www://www.esefa.uct.ac.za/esefa/joining-esefa/universities

The ESEFA programme is working within Africa to teach Enterprise Systems skills to Information Systems, Informatics, Computer Science and Information Technology students so that these skills are more available and affordable to adopting organization ${ }^{2}$.ESEFA, apart from educating Africans on the benefit of ERP adoption, is also building enterprise system capacity for Africa. This will help Africa to increase her ICT skill base and to provide the necessary work force needed in the implementation of ERP and other Information and Communication Technology/Information System (ICT/IS) related jobs. This is a right step in the right direction and we encourage more African universities to join. 
The ESEFA programme is delivered as SaaS to the member university. The member university submits the range of her Internet Protocol (IP) address to SAP for her to log on unto the ESEFA server that is in the University of Cape Town, South Africa for examination and the workshops. University of Cape Town, South Africa is a primary stakeholder while the other universities are partners. University of Nigeria, Nsukka (UNN) South East Nigeria became a member of SAP University Alliance in 2016. University of Nigeria, Nsukka is running the ESEFA programme and she is encountering challenges in the following areas: Network Limitations, Limited Power Supply, Inadequate Top Management Support and Lack of Technical Support.

Faasen et al (2013) focused on understanding of the intention to adopt SaaS ERP software in the specific context of South African SMEs. They found that the system performance and availability risk, loss of control and lack of vendor trust are the factors that caused a reluctance to adopt SaaS ERP in this context. Factors like Network Limitations, Customization, Security and Cost Concerns were identified to be the barriers to selection of a SaaS ERP in SouthAfrica (Lachesa et al.,2012). Hence, they suggested that further investigation on how these factors influence the acquisition decision may help to correctly manage the selection process (Tobie et al 2016).

ERP can also be delivered as open-source. This can also reduce both hardware and software costs. Given the weak adoption of these systems in Africa, Tome et al (2014) identified the factors that prevent the choice of this type of ERP. They found that Lack of Knowledge, Lack of Sizable Providers (or Vendors) and Ironically Low Costs might be the barriers to open-source ERP adoption (Tobie et al, 2016).

Moohebat M.R. and Jazi, M.D. (2010) set out to understand if there is any difference between ERP implementation's critical success factors (CSF) in developed and developing countries. Their research was based on previous researches like the work of Nagi et al (2008) which classified CSFs into eighteen main groups. The said CSFs are listed below: "Appropriate business and IT legacy systems", "Business plan/vision/goals/justification", "Business Process Reengineering", "Change Management", "Communication", "Data accuracy", "ERP strategy and Implementation", "ERP project team", "ERP vendor", "Monitoring and evaluation of performance", "Organizational characteristics", "Project champion", "Project management", "Software Development, testing and troubleshooting", "Top management support", "Fit between ERP and business/process", "National culture" and "Country-related functional requirements". Their research showed that "change management" was the most important factor and "fit between ERP and business process reengineering (BPR)" were the least cited critical factor in ERP implementation in different countries of the world (developed and developing). Developing countries underestimate business process reengineering (BPR) and fit between ERP and business/process factors. The paper concluded that national culture has impressive effect on ERP implementation in developing countries. Also developing countries companies depend more on ERP vendors than developed countries companies.

Saad Ghaleb Yuseen (2009) examined the essential factors that enable or inhibit the success of ERP implementation in a knowledge-based pharmaceutical industry in Jordan. The result of his analysis showed that problems of the management's approach of implementing ERP, user's acceptance, trust, work habits and cultural attitudes all have both direct and indirect effects on the ERP system usage. He further stated that end users lack of acceptance of ERP systems is one of the main reasons why ERP implementations fail to achieve the expected benefits. In addition, the big bang approach of implementing ERP systems is not suitable to the organizational environment in the said pharmaceutical case study. Morteza Moalagh and Ahad Zare Ravasan (2013) stated that an ERP implementation can be considered successful if and only if managerial success, organizational success and individual success take place simultaneously. They believed that this holistic view will lead organizations to obtain effectiveness and align ERP systems with a balanced organizational outlook. 
Goeun (2013) showed how ERP systems achieve the major goal of increasing operating efficiency by improving business processes and decreasing costs. McGaughey and Gunasekaran (2007) explained the evolution of ERP systems from materials requirement planning (MRP) to manufacturing resource planning (MRPII) to enterprise resource planning (ERP) to ERPII and finally to interprise resources planning (IRP) or enterprise system (ES). The paper identified two primary drivers in the evolution of ERP as business and technology needs. It is not always an easy task to meet the two needs harmoniously and simultaneously. Figure 1 below shows the evolution of ERP by McGaughey and Gunasekaran 2007.

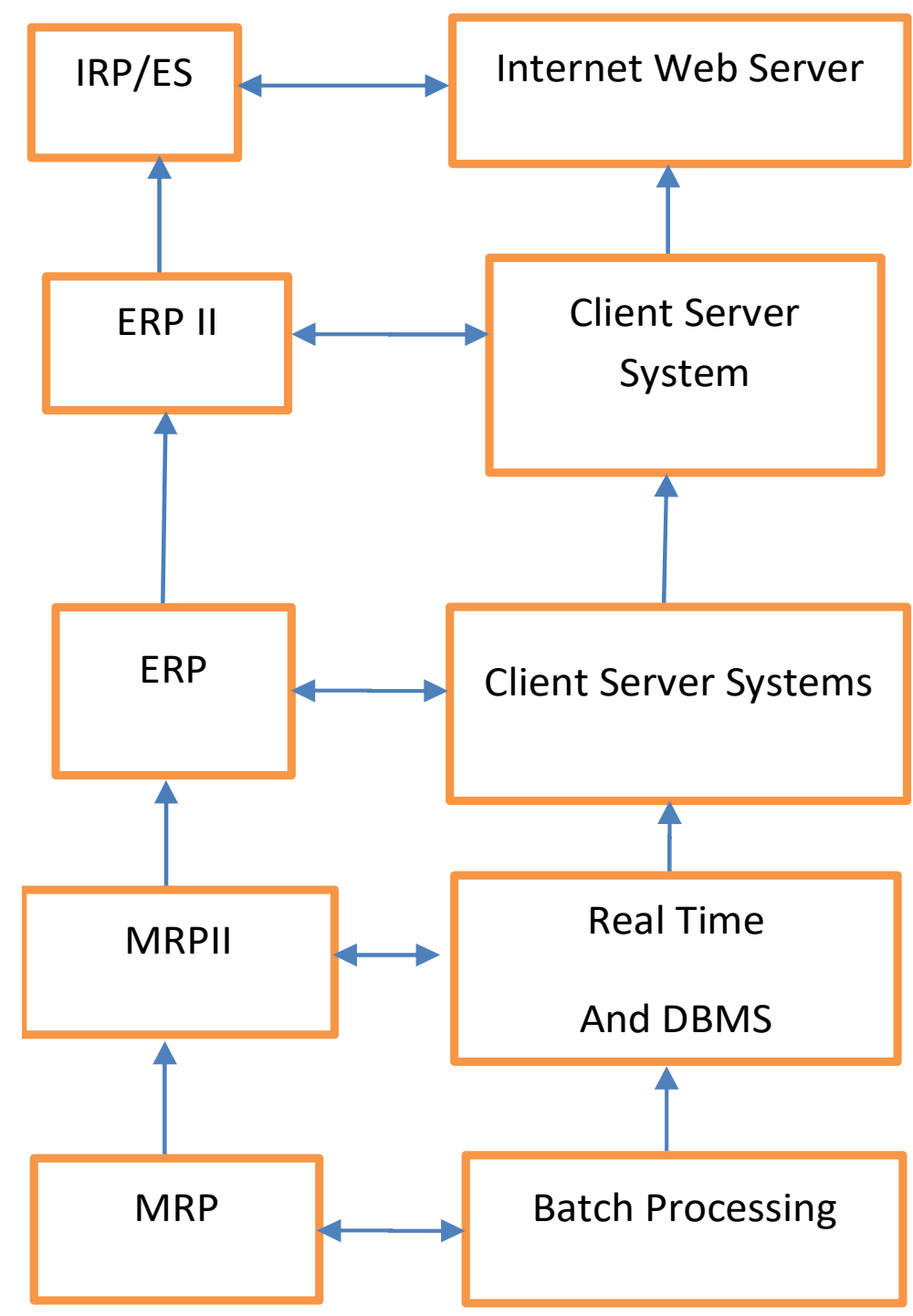

Figure1: The Evolution of ERP and Its Enabling Technologies

(Source: Mcgaughey and Gunasekaran, 2007) 


\section{CHALLENGES AND ISSUES OF ENTERPRISE SYSTEMS IMPLEMENTATION IN DEVELOPING COUNTRIES}

Enterprises worldwide have adopted ERP systems to leverage business performance (Beheshti \& Beheshti, 2010), and ERP systems have become one of the most widespread IT solutions in organizations (Al-Mashari et al., 2003). ERP has been implemented extensively and adopted widely in Europe and North America, but developing countries still lag behind (Mukti et al., 2016; Huang \& Palvia, 2001). Irrespective of the level of development, the challenges faced by ERP implementers stemmed majorly from the organizations and human related issues such as incompatible business processes, organizational culture that resist change, mismanagement of project, lack of commitment from management, constraints related to the nature of available information and communication technology (ICT) infrastructure, lack of investment in business research and development (Helo et al, 2008; Nzuki \& Okelo-Odongo, 2015). Different challenges have been outlined by various studies ranging from lack of commitment from top level management, improper implementation strategy, improper vendor selection, project management training and development, quality of business process re-engineering and user participation to lack of experienced implementation team, (Mukti \&Rawani, 2016). In addition to the challenges that are common to every organization that is implementing ERP systems, developing countries are faced with a myriad of peculiar challenges and issues in the implementation of ICT related systems. The issues of corruption, mediocrity, land lord and land lady syndrome(a situation where some group of people feel that they own the land/organization/state and that only what they say will be carried out) greed and un-patriotism should be properly addressed (Inyiama \& Ebem, 2005 not available online).

ERP provides services to all departments in an organization. It provides the enterprise with capacity to plan and manage its resources based on an approach that aims to integrate processes, functions and activities in an organization (Soltanzadeh \& Khoshsira, 2012). They saw ERP system from a technology transfer perspective and summarized CSFs that integrate the concepts of ERP implementation and Technology Transfer (TT) in four Iranian Companies. They identified five main factors viz culture, organizational structure, project management, support activities \& training issues and the interaction between transferor and transferee. They posit that if these factors are properly handled/ managed, complicated challenges in ERP implementation will decrease and there will be increase in success chance of implementation.

Khalifa and Azab (2012) examined the issues that might face key players in different Egyptian industrial sectors before or while implementing ERP systems. The issues are enumerated below: drivers, challenges, critical success factors and the extent of success realized. Cross-industry case studies were conducted on both ERP adopters and nonadopters to measure the perception of decision makers about ERP implementation. Ranjan et al (2016) did a thorough review and analysis of the literature on the challenges faced in ERP implementation with respect to technology selection, change management, knowledge management and emerging technologies. They stated that if organizations consider these issues, they would realize several benefits such as reducing costs and also save time and extra effort. Huang and Palvia (2001) identified a range of issues associated with ERP implementation in developing countries. The challenges/issues are economic, cultural and basic infrastructure. They proposed a framework for ERP implementation and used the proposed framework to compare ERP implementation in developed and developing countries.

The target of ERP is the whole enterprise(Huang \& Palvia, (2001) and it involves huge sums of money and human resources so any company that wants to embark on ERP implementation should ensure that she understands ERP associated challenges/issues and handles them effectively and efficiently, else the company will be disappointed. Huang \& Palvia (2001) enumerated the characteristics of ERP implementation in developed and developing countries. This is given in table 2 . 
Table 2: ERP Implementation Characteristics For Developed And Developing Countries

\begin{tabular}{|l|l|l|l|}
\hline S/N & Characteristics & Developed & Developing \\
\hline 1 & Excellent infrastructure & Yes & No (Poor) \\
\hline 2 & Strong economic base and growth & Yes & No \\
\hline 3 & Good Governmental IT policy & Yes & No \\
\hline 4 & Deregulation and organisational enthusiasm for IT & Yes & No \\
\hline 5 & $\begin{array}{l}\text { New technology like ERP, SCM are quickly } \\
\text { absorbed by organizations in almost all industries }\end{array}$ & Yes & No \\
\hline 6 & Poor national/ environmental factors & No & Yes \\
\hline 7 & Poor economic status and economic growth & No & Yes \\
\hline 8 & Bad government regulations & No & Yes \\
\hline 9 & $\begin{array}{l}\text { Partial existence of infrastructure such as } \\
\text { transportation, }\end{array}$ & No (Full existence) & Yes \\
\hline $\begin{array}{l}\text { telecommunication, internet and intranet, mobile } \\
\text { telecommunications and public database systems }\end{array}$ & & \\
\hline 10 & Low IT maturity & No & \\
\hline 11 & Small firm size & No & Yes \\
\hline 12 & Lack of process management orientation & No \\
\hline 13 & Lack of Business Process Reengineering(BRP) & No & Yes \\
\hline 14 & Lack of computer culture & No & Yes \\
\hline 15 & Lack of ERP expertise & No & Yes \\
\hline 16 & Low BRP experience & No & Yes \\
\hline 17 & $\begin{array}{l}\text { Governmental policies encouraging foreign } \\
\text { investments }\end{array}$ & Yes & Yes \\
\hline 18 & Fair competition & No \\
\hline 19 & Insecurity/insurgency & No (minimal) & No \\
\hline 20 & Terrorism & Yes & Yes (huge) \\
\hline 21 & Hate speeches & Yes \\
\hline
\end{tabular}

ERP is in its early stages in developing countries and the actual experience of using IT to design business processes is limited in developing countries. Developing countries should borrow a leaf from developed countries and make available the various factors that enhance IT adoption and ERP penetration. Asamoah et al,(2015) in order to understand the impact ERP implementation has on process outcome in Sub Saharan African context replicated a study made in the US within the context of Ghana. Contrary to the previous study, there were no relationship between the level of implementation and the process outcome in the Ghanaian context. The authors raised hence the importance of the local context of the study. This means the necessity to take care of the contextual variables when studying ERP implementation.

Suraj (2016) highlighted a lot of challenges and issues that are associated with ERP implementation in developing countries. In this paper, we have attempted to summarize these challenges and issues under major challenge/issue categories which include but not limited to: Training/development, process management, leadership, infrastructural, change management, economic, infrastructural/hardware, maintenance and support structure, regulation, risk, culture. Details of each of these challenge categories and the sub-items associated with them are shown in table 3 below. 
Table 3: Issues and Challenges of ERP Implementation in Developing Countries

\begin{tabular}{|c|c|c|}
\hline S/No. & Category of Challenge/lssues & Challenges/lssue Category \\
\hline 1 & Training/Development & $\begin{array}{l}\text { Lack of computer-based training, lack of } \\
\text { experienced implementers, human resources } \\
\text { development, awareness }\end{array}$ \\
\hline 2 & Process Management & $\begin{array}{l}\text { Non-uniform practice, process management, ERP } \\
\text { system misfit, }\end{array}$ \\
\hline 3 & Leadership & $\begin{array}{l}\text { Lack of vision and planning, the establishment of } \\
\text { knowledge transfer systems, project management, } \\
\text { legacy system management, lack of clearly defined } \\
\text { goal of implementation, team composition. Lack of } \\
\text { top management support, project management, } \\
\text { right people for the right work. }\end{array}$ \\
\hline 4 & Infrastructural & $\begin{array}{l}\text { Power, internet access, system upgrade, training } \\
\text { facilities. }\end{array}$ \\
\hline 5 & Change Management & $\begin{array}{l}\text { Resistance to change from end users and functional } \\
\text { managers. }\end{array}$ \\
\hline 6 & Economic & $\begin{array}{l}\text { Infrastructure, business size, manufacturing size, } \\
\text { limited resources }\end{array}$ \\
\hline 7 & Infrastructural/hardware & Suitability of hardware \\
\hline 8 & $\begin{array}{l}\text { Maintenance and Support } \\
\text { Structure }\end{array}$ & $\begin{array}{l}\text { Non-competent consultant, selection of ERP vendor, } \\
\text { quality assurance, software } \\
\text { configuration and institutionalization }\end{array}$ \\
\hline 9 & Regulation & Lack of political environment. \\
\hline 10 & Risk & $\begin{array}{l}\text { Data security, lack of alignment of ERP systems with } \\
\text { organizational processes, }\end{array}$ \\
\hline 11 & Culture & Dissimilar cultural context \\
\hline
\end{tabular}

The various literatures reviewed show that developing countries still have a lot to do in order to successfully adopt and implement ERP. Our work also agrees with other literatures that developing countries like Africa are experiencing myriads of problems/issues/challenges as listed in tables 2 and 3 above. Some problems are ICT/technology related, some human related, some environmental/governmental and religious/tribal. It posits that concerted efforts should be made to minimize/eradicate those problems in order for them to benefit maximally from ERP systems and become globally relevant and visible. Figure 2 below shows our proposed ERP Evolution for Africa. 


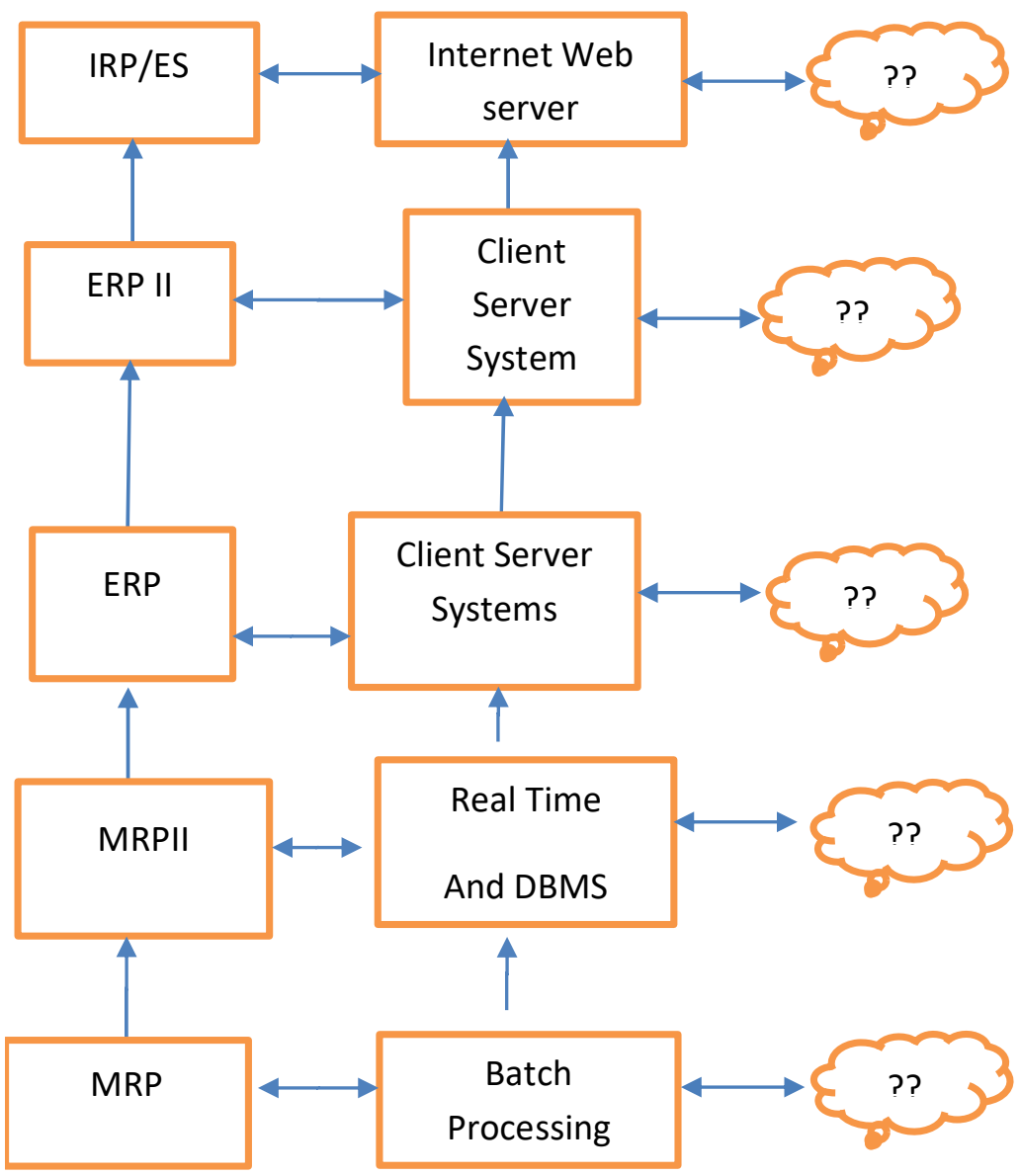

Figure 2: Our Proposed ERP Evolutional Framework for Africa.

In this framework the challenges/issues are represented by two question marks (??) in the cloud callout.

\section{ERP OF THE FUTURE FROM A GLOBAL PERSPECTIVE AND THE POSITION OF AFRICA.}

Emphasis on customer satisfaction, the wake of e-commerce, and the need to integrate supply chain management (SCM) and technological advancement have shifted attention from traditional ERP systems to Enterprise systems (ES) which integrate both the internal and external business processes and systems (Li Da Xu, 2011). A typical supply chain consists of institutions and actors that are concerned with the production and distribution of goods and services to the consumers. It includes suppliers, manufacturers, warehouses, distribution centers, stores and other institutions that play facilitating roles. SCM as a strategic approach seeks to integrate these institutions and actors in such a way that, what is needed by the customer is produced in the right quantity and at the right time while keeping all the associated system cost at a minimal level. Customer satisfaction and system cost minimization is at the center of supply chain management. Before now, ERP systems were regarded as 'back office' because the activities and processes that are internal to the enterprise were only considered in the design (McGaughey and Gunasekaran, 2007). Changes in the technological environment, vendor plan, and changes in the business environment have contributed in reshaping the future of ERP systems. The effect of the changes on ERP systems is more for developed countries than developing countries. 
The advancement in technology has further given rise to a new multipurpose business model, which is centered not only on customer satisfaction but also on collaboration network (McGaughey and Gunasekaran, 2007) which is the major factor behind the fast growth of e-commerce. The reason why business organizations are focusing attention on external integration is that of the need to include supply chain management (SCM). SCM is believed to be the key to enhanced cross-enterprise collaboration and inter-enterprise processes (Reddy, 2002; Ryan, 2002). According to Xu (2011), intra-organizational integration is concerned with the interconnection of business processes within the enterprise. On the other hand, the inter-organizational integration is an effort towards filling the gap of early ERP systems which was only concerned with business process coordination and integration within a system by moving a step further to integrate external systems. Inter-organizational systems aim to support SCM which older ERP systems lacked the capacity to realize. Scholars see this high level of integration as complex and have tried to propose models to address the challenge (Fox et al, 1993; Hazel, 2000; Wolfert et al, 2010). These authors, however, have failed to identify the fact that while developed countries are trying to take a step ahead, developing countries are yet to be abreast with the traditional ERP systems back office functionalities due to bottlenecks that emanate from lack of process technology employee (Carutasu, 2006). This situation often leads to conflict among users.

Moreover, most enterprises in developing countries have their legacy systems which vendors and developers of enterprise systems software should work hard to bridge (Seo, 2013). On the global perspective, ERP adoption is moving towards SaaS, Application Service Providers (ASP), Radio Frequency Identification (RFID), open source and cloud computing which reduce hardware and software costs. It is also tending towards intra and inter organizational system integration. A major benefit of the RFID technology is that the supply chain will become more visible to management, and labour costs within supply chain can be reduced (Xu, 2011; Beheshti \& Beheshti, 2010). As outlined in recent research from Forrester, seven technologies will drive this transformation: SaaS, Mobile, Business Process Modeling (BPM), usability by making these apps user-friendly and adding advanced analytics capabilities, Platformas-a-Service (PaaS), Social networks and elastic computing.

Martens (2013) analyzed that many ERP vendors debuted product or fleshed out their strategies for SaaS ERP in 2012 and further developments are set for future with focus on SaaS ERP, SaaS offering in hybrid harmony with on-premise ERP, PaaS and Infrastructure -as-a-Service (laaS) strategies. Given the success of SaaS CRM and SCM (Customer Relationship Management and Supply Chain Management), SaaS financials seem to be the next area likely to resonate with a larger set of enterprise customers (Ranjan, et al 2016). Addo-Tenkorag and Helo (2014) proposed ERP-SaaS model with industrial systems solution value-adding benefits including: low preliminary-and-anticipated on-going costs, faster implementations and value-adding, affordable ownership cost, greater flexibility, improved support, reduced IT complexity and improved business motivation (Ranjan, S. et al 2016). E-commerce, m-commerce, plug-and-play software modules, service-oriented architecture, and internet based architecture will take a prominent place in the future ERP systems. They will be the key in meeting evolving business needs and on the flip side; one can argue that the evolving technologies will give rise to new business needs (McGaughey \& Gunasekaran, 2007).

Web services are expected to play a prominent role in the future of ERP. The use of "best in breed" web service-based solutions might be more palatable to businesses, since it might be easier and less risky to plug in a new web servicebased solution than replace or add on a new product module. Data warehouses, data mining and various analytic capabilities are needed in support of front-office and back-office processes and activities involved in CRM, Supplier Relationship Management (SRM),SCM, field service management, business collaboration and more. Knowledge management systems(KMS) endowed with neural networks and expert system capabilities will play a key role in decision making as they become more able to capture, model and automate decision making processes (McGaughey and Gunasekaran, 2007). McGaughey and Gunasekaran (2007) opined that the ERP of the future will hinge on the same forces that shaped the ERP of the past. The two forces identified are business needs and technological change. 
They advised researchers and practitioners to focus on monitoring business needs and technological changes and gear their researches towards bringing the two together. As for the name it will be called, they stated that it may be called ERPII or Interprise Resource Planning (IRP), Enterprise Suite (ES), Enterprise System (ES) or a name that is currently residing in the back of some vendor, employee or researchers mind. Whatever it will be called, ERP of the future will be found at the convergence of business need and technological change. Africa is still struggling with present ERP, for her to adopt and implement the ERP of the future seems an illusion/ an uphill task. If Africa is overwhelmed with the present ERP, how will she cope with the ERP of the future, from global perspective? This is a million questions that should be answered by Africa.

\section{DEVELOPING A FRAMEWORK FOR FUTURE OF ENTERPRISE SYSTEMS IN AFRICA.}

A big wall of difference exists between developed and developing countries technologically. ERP implementation in Asia is very low (Rajapakse \& Seddon, 2005) and it is worse in Africa. African countries are far behind (Tobie et al., 2016; Mukti \& Rawani , 2016). To close the gap between developed countries and Africa, it is necessary that developing nations like Africa should implement ERP in their organizations with more vigor and zeal (aggressively). Some countries in Africa (South Africa, Kenya, Malawi, Mauritius, Zambia, Zimbabwe, Egypt, Ethiopia, Libya, Nigeria, Botswana, Ghana, Mozambique, Sudan and Zambia) have implemented and adopted ERP (Tobie et al, 2016). However, the number is insignificant compared to the size of Africa, only thirteen (13) countries out of fifty- three (53) (Tobie et al. 2016).

The reasons behind the broad and noticeable difference in ERP systems implementation between developed and developing countries are not far from the issues and challenges described above. Apart from infrastructural problems and poverty, developing countries are still battling with processes standardization, human resources development, and cultural issues. Most processes in developing countries are not standardized; hence, the need for business process re-engineering (Olson, 2005; Ehie, 2005). Without having standards in place, process integration as part of the pillar on which ERP systems rest will not be realized for African nations.

The second aspect of today's enterprises in developed countries is external integration which gave rise to a robust network which includes other major external actors of business, e.g. suppliers and customers. It is still a far-off dream for developing countries because their internal environment needs to be integrated properly first before the external environment. With this, vendors and designers of ERP systems for developing countries are expected to develop systems that will take into consideration the level of ERP implementation of developing countries and not develop a uniform system for the two economies. Without this framework, developing countries will be left behind in the ERP of the future.

This paper is of the view that, the functions of the traditional ERP systems which lay emphasis on the back office should, first of all, be explicitly understood, implemented, and used by enterprises in developing countries before the introduction of new ERP systems. It is like bringing up the old ERP system to be housed in the new technological framework that uses the internet and mobile technology. Even though developing countries are now part of the global village and use the same technology with developed countries like the internet and mobile technologies, they are yet to be fully abreast with the use of old ERP systems which has back office functionalities. It is with exception to few multinational and large organizations within developing countries that have been using ERP technology for quite some time. 
In addition to the above, a framework for future implementation of ERP systems in Africa would require training and development of IT personnel to operate the systems and the development of support and maintenance systems. It will help to avoid the pitfall of having to import IT personnel from developed countries, which has a huge cost implication. Without having these personnel on the ground, the ERP systems in developing countries will invariably be characterized by systems failure. Authors have noted that integrated supply chain management is the key to enhanced cross-enterprise collaboration and inter enterprise processes (Reddy, 2002; Ryan, 2002) and fills between old ERP systems and current ES systems. African countries do not yet have the capacity for this level of integration due to the bottleneck that emanates from the lack of process technology employee (Carutasu, 2006). More so, enterprises in developing countries have their legacy systems which require concerted efforts to bridge (Seo, 2013). Since businesses in developing countries are known by weak capital base and cash flow, the future of enterprise systems in Africa will require a platform that will make it easy for the businesses to re-use already existing data and systems through data interchange systems which are adaptable to developing countries, judging from their level of technological advancement. This platform has to create room for information, systems, and applications to be integrated into ERP systems without significant changes in application cost and data which is a good way to minimize cost. Has Africa taken care of the challenges and issues that militate against the successful implementation of an ES/ERP system? The answer is no. As long as those problems are not solved, Africa will continue to lag behind.

\section{THE WAY FORWARD}

Africa should make conscious efforts to close the gaps by providing adequate and needed infrastructure, good governance, use of competent and qualified professionals, cultural readiness, training, maintenance and adequate hardware and software upgrades, the economic strength, the necessity of integrated business processes (Soltanzadeh, and Khoshsirat, 2012 Khalifa and Azab 2012. The right consultants should be chosen, using their skills as well as their knowledge appropriately and transferring as well as internalizing necessary knowledge within the organization is essential to the overall success of an ERP system implementation. In addition, fostering an open culture and encouraging open communications can facilitate success in ERP implementation (Mei-Hsia Chiang, 2013).ESEFA is at the forefront of educating Africans on ERP systems and the associated benefits. Presently some universities in Africa are now members of SAP University Alliances as shown in table 1(section 4) above. These universities are training staff and students on SAP ERP and enterprise system as a course. Therefore, we encourage more universities to join.

\section{CONCLUSION}

There are gaps in the adoption and implementation of ERP in developed and developing countries. Those gaps are caused by the challenges highlighted above (infrastructural, poor economy, culture, government policies, lack of awareness/education). Government policies that discourage foreign investment and fair competition will adversely affect ERP implementation and adoption. Government at all levels should encourage foreign investment and fair competition, IT diffusion, remove barriers to the introduction of IT and ERP systems for these will boost ERP implementation and adoption. Proper education and training, provision of needed infrastructure (energy, the internet, enabling environment), good governance and the rule of law can close those gaps. Even though it seems that Africa is coming up by using internet and web servers, the adoption, implementation and realization will take time. To bring Africa close to the level of the developed world, we have given a model for Africa which we believe that if properly implemented, the needed result will be achieved. The model is given in section 5 above. In that model, the challenges/issues are represented by two question marks (??) in the cloud callout. We suggest that those challenges should be given immediate attention; else Africa will still lag behind in the implementation of ERP.

This implies that the future of ERP implementation in Africa appears bleak. But if the challenges are taken care of, the 
future of ERP implementation in Africa will be bright. Future research will include: empirically testing and refining the framework and exploring relationships among the various challenges/issues. Case studies and field studies may be used to carry out such researches.

\section{REFERENCES}

1. Addo-Tenkorang, R. and Helo, P.T. (2014), "ERP SaaS value chain: a proposed SaaS model for manufacturing SCM networked activities", International Journal of Business Information Systems, Vol.17 No.3, pp. 355-372.

2. Al-Mashari, M. and Al-Mudimigh, A. (2003), "ERP implementation: lessons from a Case study", Information Technology and People, Vol.16 No.1, pp. 21-33.

3. Akeel,H.,Wynn, M.G. (2015), "ERP Implementation in a Developing World Context: A Case Study of the Waha Oil Company, Libya". In eknow $20157^{\text {th }}$ International Conference on Information, Process and Knowledge Management, pp. 126-131. Think Mind.

4. Akeel, H., Wynn, M. and Zhang, S. (2013), "Information Systems Deployment in Libyan Oil Companies: Two Case Studies", The Electronic Journal of Information Systems in Developing Countries, Vol. 59 No .4, pp.118.

5. Beheshti and Beheshti, 2010, "Improving productivity and firm performance with Enterprise resource planning", Enterprise Information Systems, Vol. 4 No. 4, pp. 445-472.

6. Bhattacharjee, D., Greenbaum, J., Johnson, R., Martin, M., Reddy,R., Ryan,H.L.,et al (2002), Intelligent Enterprise, Vol. 5 No. 6, pp. 28-33.

7. BongsugChae and SheuChwen (2005), "Issues in multinational ERP Implementation", International Journal of Services and Operations Management, Vol. 1 No. 1.

8. Boltana, A.S., \& Gomez, J.M. (2012), "A Successful ERP Implementation in an Ethiopian Company: A Case Study of ERP Implementation in Mesfine", Industrial Engineering Pvt. Ltd. Procedia Technology, Vol. 5, pp. 40-49.

9. Ehie I. C. (2005), "Identifying critical issues in enterprise resource planning (ERP) implementation", Journal of Computers in Industry -Current trends in ERP implementations and utilization, Vol. 56 No.6, pp. 545-557.

10. Fox, M, Chionglo, J. Barbuceanu (1993), "The integrated supply chain management system." Internal report .Dept. of Industrial Engineering, University of Toronto.

11. George Căruţaşu and Cristiana Bucur (2006). "ERP implementation issues", Proceedings of the 15th International Conference on Manufacturing Systems - ICMaS. pp. 516-518

12. GoeunSeo (2013), "Challenges in Implementing Enterprise Resource Planning (ERP) system" Thesis (S.M.)-Massachusetts Institute of Technology, Sloan School of Management, pp. 53-56.

13. Grabski, S.V., Leech, S.A., and Schmidt, P.J. (2011), "A Review of ERP Research: A Future Agenda for Accounting Information Systems", Journal of Information Systems, Vol. 25 No.1, pp. 37-78.

14. Hammerman, P.D. (2011), "Forrester: Seven Trends to Shape the Future of Enterprise Applications and ERP, Forrester". [Online] http://www.computerweekly.com/news/2240105104/Forrester-Seven-trends -to- shapethe- future- of- enterprise- applications- and- ERP

15. Hasselbring, W. (2000), "Information system integration", Communications of ACM, Vol.43 No.6, pp. 32-38.

16. Huang, Z. and Palvia, P (2001), "ERP Implementation Issues in Advanced and Developing Countries", Business Process Management Journal, Vol.7 No.3, pp. 276-284.

17. Inyiama, H.C. and Ebem, D.U. (2005), "Developing Academia and Industry Collaboration Process for Nigeria", Journal of Information, Communication and Computing Technologies (JICCOTECH) A Publication of ICT/Research Centre Ebonyi State University, Abakaliki not online. 
18. Kataev M.Y.,Bulysheva, L.A.,Emelyanenko,A.A, Emelyanenko V.A(2013), "Enterprise systems in Russia:1992-2012", Enterprise Information Systems Vol.7 No.2. pp.168-186

19. Kam,(2012) "Knowledge Assessment Methodology by the World Bank", www.worldbank.org/Kam.

20. Kumar, K and Hillegersberg, J.V. (2000) "ERP Experiences and Evolution", Association for Computing Machinery. Communication of the ACM, Vol.43 No.4, pp. 22-26

21. Markus, M.L., Tanis, C., and Van Fenema, P.C. (2000), "Multisite ERP implementations", Association for Computing Machinery. Communications of the ACM, Vol. 43 No. 4, pp.42-46.

22. Martens, C. (2013) http://scn.sap.com/community/businesstrends/forresters-thoughts-for-2013-erp-trendsrevealed (accessed on 2th February 2017).

23. McGaughey,R.E and Gunasekaran A. (2007), "Enterprise Resource Planning (ERP): Past, Present and Future", International Journal of Enterprise Information Systems, Vol. 3 No.3.

24. Mei-Hsia Chiang,(2013), "Organizational Change in ERP Implementation: A dialectical Perspective", The Journal of Global Business Management, Vol. 9 No.1, pp. 175-185.

25. Momoh A., Roy, R., \& Shehab, E. (2010), "Challenges in Enterprise Resource Planning Implementation: State-of-the-Art", Business Process Management Journal, Vol. 16 No. 4, pp. 537-565.

26. Moon, Y.B. (2007), "Enterprise Resource Planning (ERP): A Review of the Literature", International Journal of Management and Enterprise Development, Vol. 4 No. 3, pp. 235-264.

27. Morteza Moalagh, A. Z. Ravan. (2013), "Developing a practical framework for assessing ERP postimplementation success using fuzzy analytic network process", International Journal of Production Research, Vol. 51 No. 4, pp. 1236-1257.

28. Mukti et al (2016), "ERP system implementation issues and challenges in developing nations", ARPN Journal of Engineering and Applied Sciences, Vol. 11 No. 12, pp. 7989-7996.

29. Mukwasi,C.N and Seymour, L.F.(2012), "Enterprise Resource Planning Business Case Considerations: A Review for Small and Medium -Sized Enterprises", Journal of Innovation Management in Small and Medium Enterprises.http://www.ibimapublishing.com/journals/JIMSME/2012/752328 /752328.pdf

30. Mukwasi, C.N and Seymour, L.F. (2014), "The Growing Trend of Small to Medium- Sized Enterprises Adopting Enterprise Resource Planning Systems: An Analysis of Business Cases in Zimbabwe and South Africa", Journal of Emerging Trends in Economics and Management Sciences, Vol. 5 No. 7, pp. 138-145.

31. Mukwasi, C.N and Seymour, L.F. (2015), "Independent Enterprise Resource Planning Risks in Small and Medium-Sized Enterprises in Developing Countries", In $1^{\text {st }} \quad$-Africa Conference Proceedings, http://www.researchgate.net/publication/275351574

32. Nzuki, D.M and Okelo-Odongo, W (2015), "Adoption of Enterprise Resource Planning Systems in Kenya: A Case of Selected Manufacturing Firms in Nairobi Metropolita", International Journal of Business, Humanities and Technology, Vol. 5 No. 2, pp. 24-32.

33. O.Zach (2012), "ERP implementation in SMEs: exploring the influences of the SME Context" Faculty of Economics and Social Sciences, University of Agder, Doctoral Thesis.

34. O'Leary, D. E. (2000), "Enterprise Resource Planning Systems: Systems, Life Cycle, Electronic Commerce, and Risk", UK: Cambridge University Press.

35. Qureshi.,(2005), "Enterprise Application Integration", International Conference on Emerging Technologies, Vol. 17 No. 18, pp. 340-345

36. Rajapakse J., "ERP Adoption in Developing Countries in Asia: A Cultural Misfit" https://www.semanticscholar.org

37. Ranjan, S., Jha, V.K. and Pal, P. (2016), "Literature review on ERP implementation

38. Challenges', Int. J. Business Information Systems, Vol. 21 No. 3, pp. 388-402.

39. Ross, J.W. \& Vitale, M.R. (2000), "The ERP Revolution: Surviving vs. Thriving", Information Systems Frontiers, Vol. 2 No. 2, pp. 233-241. 
40. Saad Ghaleb Yuseen (2009), "Critical Factors Affecting Enterprise Resource Planning Implementation :An Explanatory Case Study", International Journal of Computer Science and Network Security, Vol. 9 No. 4, pp. 359-363.

41. Seymour,L.F., \& van Vuuren, I.J. (2014), "ERP User Adoption Constraints: A Significant Risk for Emerging Economy SMEs", Proceedings of the 16th International Conference on Information Integration and Webbased Applications \& Services, pp. 499-507

42. Sanja, M.M (2013), "Impact of Enterprise Resource Planning System in Health Care", International Journal of Academic Research in Business and Social Sciences, Vol. 3 No. 12, pp. 404-418.

43. Serima, P.(2014), "Africa needs investment in technology and talents. Business IT Africa (South Africa)", Conference on Information Integration and Web-based Applications \& Services, pp. 499-507.ACM

44. Tobie, A.M.et al (2016), "A literature review of ERP implementation in African Countries", The Electronic Journal of Information Systems in Developing Countries, Vol. 76 No. 4, pp. 1-20.

45. Wolfert, J.et al, 2010, "Organizing information integration in agro-food - a method based on A service oriented architecture and living lab approach", Computers and electronics in Agriculture, Vol. 70 No. 2, pp. 389-405.

46. Xu ,Li Da ,(2011), "Information architecture for supply chain quality management" International Journal of Production Research, Vol. 49 No. 1, pp. 183-198.

47. ${ }^{1 h}$ htp:www://www.esefa.uct.ac.za/esefa/joining-esefa/universities

48. ${ }^{2}$ Anjali Ramburn, Patrick Wirz, Gwamaka Mwalemba and Lisa Seymour ES Fundamentals for Business Enterprise Systems Education For Africa (Unpublished Work). 